\title{
CONTENTS OF VOLUME II.
}

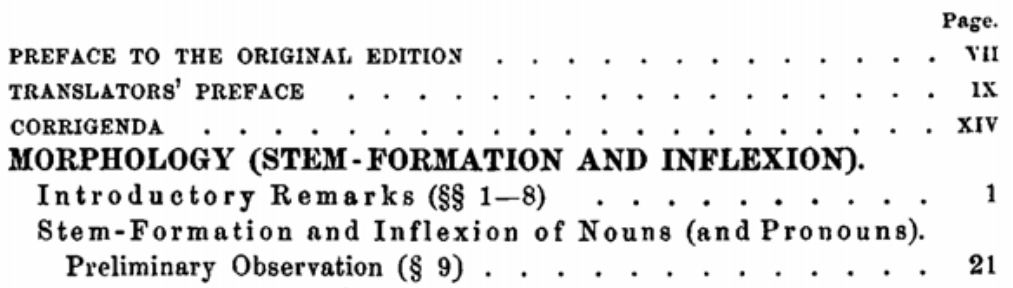

Noun-composition (Compound Nouns).

Form of the compounds.

Division into four classes $(\S 10)$. . . . . . . . . . . . 21

Indo-Germanic $(\S \S 11-19) \quad$. . . . . . . . . . . . . 23

Aryan (\$§ 20-27) . . . . . . . . . . . . . . . . . 37

Armenian (\$ 28) . . . . . . . . . . . . . . . . . . . 45

Greek $(\S \S 29-32)$. . . . . . . . . . . . . . . . . 46

Italic $(\S \S 33-36)$. . . . . . . . . . . . . . . . . 57

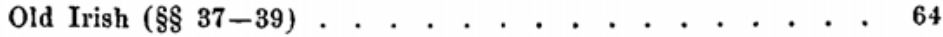

Germanic $(\S \S 40-44)$. . . . . . . . . . . . . . . . 69

Balto-Slavonic $(\S \S 45-47)$. . . . . . . . . . . . . . 78

Meaning of the compounds $(\S \S 48-50)$. . . . . . . . . . 87

Reduplicated Nouns $(\S \S 51-54)$. . . . . . . . . . . 94

Nouns with Formative Suffixes.

General Remarks (\$§ 55-58) . . . . . . . . . . . . . . 101

I. Suffixes in $-0-$ and $-\vec{a}-$.

General Remarks (§ 59) . . . . . . . . . . . . . . 109

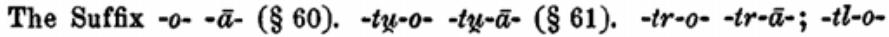

$-t l-\bar{a}-(\S 62)$. . . . . . . . . . . . . . . . . . 109

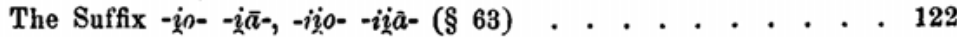

The Suffix $-u_{0}--u \bar{a}-$, $-u \iota_{0}-u \iota \bar{a}-(\S 64)$. . . . . . . . . 133

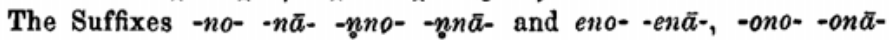

$(\S \S 65-67)$. . . . . . . . . . . . . . . . . . . 138

The Suffixes -ino- -inā- -īno- $\bar{i} n \bar{a}-$ and $-a^{x} i n o-a^{x} i n \bar{a}-(\S 68) \quad . \quad 155$ 
The Suffix -tno- -tnā-, -tnnno- $-t n n n \bar{a}-(\S 69)$. . . . . . . 160

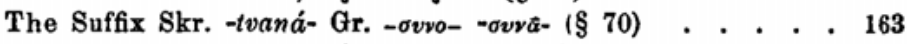

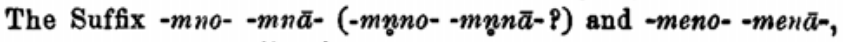

-mono- -monā- $(\S 71)$. . . . . . . . . . . . . . 163

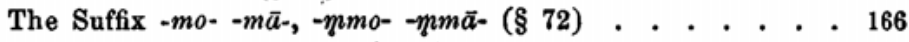

The Suffix -tinmo- tmmā- $(\S 73)$. . . . . . . . . . . 177

The Suffix -ro- -rāa-, -rro- -rrāa $(\S 74)$. . . . . . . . . 180

The Suffixes -ero- -erä- and -tero- -ter $\bar{a}-(\S 75)$. . . . . 188

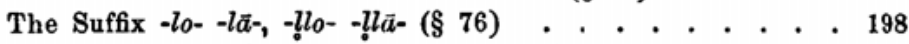

The European Suffixes $-d h-r o--d h-r \bar{a}-$ and $-d h-l o--d h-l \bar{a}-(\$ 77) 213$

The Suffix -bho- -bhā- $(\S 78)$. . . . . . . . . . . . 216

The Suffix -to- -tā- with -is-to- and -mn-to - un-to- (§§ 79-82) 218

The Suffix $-\hat{k} o--\hat{k} a-(\S 83)$. . . . . . . . . . . . . 251

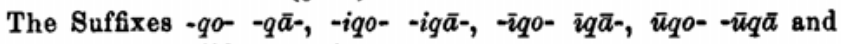
$-\ddot{a} q 0--\bar{a} q \bar{a}(\S \S 84-89)$. . . . . . . . . . . . . . . 252

The Suffixes $-s \hat{k} 0--s \hat{k} \vec{a}-$ and (Germ.-Balto-Slav.) $-i s k o--i s k \vec{a}-$

$(\S 90)$. . . . . . . . . . . . . . . . . . . . 274

The Suffix $-g o--g \vec{a}-(\S 91)$. . . . . . . . . . . . . 276

II. Suffixes in $-i$.

General Remarks (§92) . . . . . . . . . . . . 278

The Suffix $-i-(\S 93)$. . . . . . . . . . . . . . . . 278

The Suffixes -ni- (-nni-) and -eni- (oni-) (§§ 94-96) . . . 284

The Suffix $-m i-(\S 97)$. . . . . . . . . . . . . . . 289

The Suffixes -ri- (-rri-) and -li- $(-l l l i-)(\S 98)$. . . . . . 290

The Suffix -ti- (\$§99-101). The suffixes -tāti- (-tät-) and $-t \bar{u} t i-(-t \bar{u} t-)(\S 102)$. . . . . . . . . . . . . . 293

III. Suffixes in $-u$.

General Remarks (\$ 103) . . . . . . . . . . . 311

The Suffix $-u-(\S 104)$. . . . . . . . . . . . . . 312

The Suffix -iu- $(\$ 105)$. . . . . . . . . . . . . 318

The Suffix -nu- (-nnu-) $(\S 106)$. . . . . . . . . . . 320

The Suffixes rru- and $-l u-(\S 107)$. . . . . . . . . . 322

The Suffix tu- $(\S 108)$. . . . . . . . . . . . . . . 323

IV. The Suffix $-\overline{-}-(-i \bar{e}-)(\S \S 109-111)$. . . . . . . . . . 332

V. Suffixes in $-n$.

General Remarks $(\S \S 112-113)$. . . . . . . . . 340

The Suffix -en $(\S 114)$. . . . . . . . . . . . . . 344

The Suffix -ien- $(\S 115)$. . . . . . . . . . . . . 357

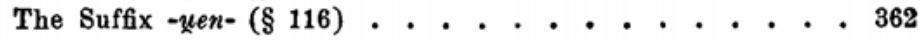

The Suffix -men- $(\S 117)$. . . . . . . . . . . . 365

VI. Suffixes in $-r$.

Nom. acc. neuter, in $-r(-\gamma-\bar{\gamma})(\S 118)$. . . . . . . 375

The Suffixes -er- and -ter- $(\$ \S 119-122)$. . . . . . 376

VII. Suffixes in $-t$.

The Suffix $-t=(\S 123)$. . . . . . . . . . . . . . . 389

The Suffixes -tāt- and $-t \bar{u} t-(\S 124)$. . . . . . . . . . 394

The Suffix -nt- $(\S \S 125-126)$. . . . . . . . . . . . 394 
The Suffix -uent- $(\S 127)$. . . . . . . . . . . . . . 404

VIII. The Suffix $-d-(-a d-)(\S 128)$. . . . . . . . . . . . 407

IX. The Suffix $-\hat{k}$ - and $-q-(\S 129)$. . . . . . . . . . . 410

$\mathrm{X}$ The Suffix $-g$ - (and $-\hat{g}-$ ?) $(\$ 130)$. . . . . . . . . . 411

XI. Suffixes in $-s$.

The Suffix -es- $(\$ \S 131-133)$. . . . . . . . . . . . 411

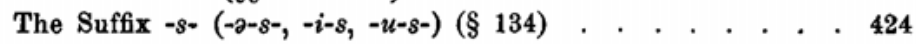

The Suffix -ies- -iies- $(\S 135)$. . . . . . . . . . . . . 426

The Suffix -ues- $(\S 136)$. . . . . . . . . . . . . . . . 438

Meaning conveyed by the Suffixes. Nouns classified from this point

of view.

General Remarks (§ 137) . . . . . . . . . . . . . 447

Adjectives.

Preliminary Observation (§ 138) . . . . . . . . . . . 448

Adjectives with Comparative Meaning (§ 139) . . . . 449

Verbal Adjectives $(\S 140)$. . . . . . . . . . . . . . 451

Denominative Adjectives (§ 141) . . . . . . . . . . 453

With Diminutival Meaning (§ 142) . . . . . . . . . . 455

Adjectives with primary suffixes whose original meaning cannot be defined $(\S 143)$. . . . . . . . . . . . . . . 455

The Relation of Adjectives to Participles (§ 144) . . . . . 456

Substantives denoting material things or persons (Concrete

Substantives).

Male and Female Sex $(\S 145)$. . . . . . . . . . . 458

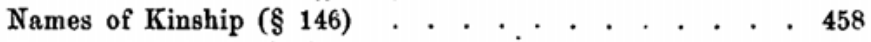

Names of Animals (\$ 147) . . . . . . . . . . . . . . . 458

Names of Parts of the Body (\$ 148) . . . . . . . . . . 459

Nomina agentis $(\S$ 149) . . . . . . . . . . . . . . . . . 459

Nomina instrumenti $(\S 150)$. . . . . . . . . . . . . . . 460

Nomina loci $(\S 151) \quad$. . . . . . . . . . . . . . . . 461

Collective Substantives (§ 152) . . . . . . . . . . . 462

Diminutives and Pet-names (§ 153) . . . . . . . . . 463

The Relation of Adjectives to concrete Substantives ( $\$ 154)$. 46.J

Substantives denoting an activity or state (nomina actionis), Verbal Abstract Nouns (§ 155) . . . . . . . . . . . 466

The Relation of the nomen actionis to the Infinitive (Supine) (§ 156) . . . . . . . . . . . . . . . . . . . 470

Substantives denoting a quality (Abstract Substantives in the strict sense) (§ 157) . . . . . . . . . . . . . . . 472

The Relation of Adjectives to Abstract Substantives (nomina actionis or substantives which denote a quality) formed with the same suffix $(\S 158)$. . . . . . . . . . . . . . 473

Nouns without Formative Suffixes (Root-Nouns).

General Remarks (§ 159) . . . . . . . . . . . . . 478

Root-nouns uncompounded (§§ 160-161) . . . . . . . 479

The nomina actionis as Infinitives (§ 162) . . . . . . . . 489

Root-Nouns as the final members of Compounds (§ 163) . . 491 


\section{SIGNS AND ABBREVIATIONS.}

* prefixed to a form indicates that it is not on record, but only inferred from other forms in the same or kindred languages. Prefixed to a root it implies that that form of the root does not occur in any word of which we have record.

$\Upsilon=$ root.

$:=$ 'to be directly compared with'.

: cp. = 'to be in part compared with' (see the Preface, p. XII).

... after $a$ form denotes that its final sounds cannot be exactly determined, (e. g. in ${ }^{*} m e \bar{e} n-s-r \ldots$ p. 186 all that is said of the suffix is that it began with $r$ ).

$a^{x}$ denotes a sound which was either $a, e$, or $o$ but cannot at present be more closely identified.

A small figure added to the name of a book denotes the edition referred to; e. g. Paul, Princip. ${ }^{2}$

Hom. A, B, $\ldots \Omega=$ Hom. Il. book $1,2, \ldots 24$.

Hom. $\alpha, \beta, \ldots \omega=$ Hom. Od. book 1, 2, . 24.

cp. = compare.

lit. = literally.

orig. = original, or originally.

esp. = especially.

scil. or sc. $=$ scilicet, i. e. the word which follows it is to be supplied in the preceding phrase.

ib. $=$ ibidem.

loc. cit. $=$ in loco citato.

Pr., O., Mid., Mod. prefixed to names of languages denote Proethnic, Old, Middle, and Modern respectively.

poss. $=$ possessive (adjectives).

dimin. = diminutive (adj. or subst.).

denom. = denominative (noun or verb).

There remain the usual abbreviations of Gender (m. f. n.), Number (sg. du. pl.), Case (nom. gen. etc.), Degree (pos. comp. superl.), Mood (ind. impv. etc.), Voice (act. med. pass.), Tense (pres. impf. etc.) and Part of Speech (subst. adj. partc. sup(ine) ger(und) etc.).

It is unnecessary to add a list of the abbreviations for the names of the languages. The latter are fully enumerated in the Introduction to the First Volume (p. 4 ff.). Observe only that A. S. = Anglo-Saxon, 0.Sax. = Old Saxon. 